\title{
Video Tour Guide Berbasis Virtual Reality Sebagai Media Informasi Fakultas MIPA Universitas Lampung
}

\author{
${ }^{1}$ Yunda Heningtyas,,${ }^{2}$ Bambang Hermanto, \& ${ }^{3}$ Muhamamad Iqbal \\ 1,2,3 Jurusan Ilmu Komputer Fakultas MIPA, Universitas Lampung \\ 1yunda.heningtyas@fmipa.unila.ac.id, ${ }^{2}$ bbg.hermanto@gmail.com, ${ }^{3}$ muhammadiqbal@ fmipa.unila.ac.id
}

\begin{abstract}
The Faculty of Mathematics and Natural Sciences is one of the faculties at Lampung University which is the center for basic knowledge. However, public interest in departments in the Faculty of Mathematics and Natural Sciences has diminished. Therefore, The Faculty of Mathematics and Natural Sciences need media to introduce and provide information in each department to prospective students and the community. The virtual tour guide is an application that combines virtual tour technology with virtual reality. This application display information about the advantages of the Faculty of Mathematics and Natural Sciences. Users can interact directly with the environment and buildings in the Faculty of Mathematics and Natural Sciences, although in the form of 3 dimensions. In addition, users are given full access to manage the information they want to know. This application, which was built using the Multimedia Development Life Cycle (MDLC) method, can be operated on an android smartphone. Based on test results, this application helps people to find out more details about the departments in the Faculty of Mathematics and Natural Sciences. However, this application can only be used on smartphones with high hardware specifications.
\end{abstract}

Keywords: Virtual Tour, Video Tour Guide, Virtual Reality, Virtual Reality FMIPA UNILA.

\section{PENDAHULUAN}

Fakultas MIPA Universitas Lampung merupakan fakultas ilmu-ilmu dasar yang menunjang universitas sebagai pusat perkembangan ilmu pengetahuan. Sejak bulan Juni 2005, Fakultas MIPA memiliki 5 Jurusan yaitu Biologi, Kimia, Matematika, Fisika, dan Ilmu Komputer [4]. Fakultas MIPA memiliki 10 gedung utama yang letaknya tersebar di seluruh wilayah Fakultas MIPA dan batasan lokasi antar jurusan juga tidak ditunjukkan oleh arah yang teratur. Selain itu, terdapat lokasi gedung yang letaknya sedikit menjorok ke dalam atau gedung dikelilingi oleh gedung-gedung lainnya [7]. Posisi gedung yang tidak beraturan tersebut membuat pengunjung sering kesulitan untuk menemukan gedung yang dituju. Fakultas MIPA telah memiliki peta lokasi gedung setiap jurusan dalam bentuk 2 dimensi (2D) yang berada pada pintu masuk dan pintu keluar Fakultas MIPA. Namun, pengunjung harus menuju pintu masuk Fakultas MIPA untuk melihat peta lokasi atau bertanya kepada petugas keamanan. Website resmi Fakultas MIPA maupun website resmi jurusan juga hanya menampilkan informasi fasilitas yang dimiliki masing-masing jurusan dalam bentuk teks dan gambar. Penyampaian informasi dalam bentuk gambar 2 dimensi (2D) dan teks dirasa belum optimal untuk menyampaikan semua keunggulan yang dimiliki masing-masing jurusan. Untuk mengatasi masalah tersebut, [7]. berhasil membangun ARMIPA (Augmented Reality Fakultas MIPA). ARMIPA merupakan implementasi dari teknologi Augmented Reality (AR) yang menampilkan gedung virtual dalam bentuk 3 dimensi (3D) jurusan Fakultas MIPA dari segala arah. Selain itu, ARMIPA menampilkan informasi jurusan dan lokasi setiap gedung. Namun, teknologi ini dirasa kurang efektif karena pengunjung harus datang ke Fakultas MIPA untuk dapat menikmati teknologi ini. Pengunjung memerlukan suatu cara yang lebih efektif untuk mendapatkan informasi detail tentang masing-masing jurusan pada Fakultas MIPA. 


\section{(C2019 Ilmu Komputer Unila Publishing Network all rights reserved}

Jurnal Komputasi

Salah satu cara yang dapat digunakan adalah pemanfaatan teknologi virtual tour untuk menyampaikan informasi dengan lebih interaktif, efektif dan efisien. Virtual tour merupakan simulasi dari suatu lokasi, biasanya tersusun atas rangkaian gambar baik foto panorama 360 derajat, video, maupun gambar 3 dimensi (3D). Virtual tour biasanya digunakan untuk memberi pengalaman "pernah berada" di suatu tempat hanya dengan melihat layar monitor. Penyajian virtual tour dapat dilakukan dengan cara memanfaatkan gambar ataupun video. Selain itu, dapat menggunakan model 3D [8]. Model 3D, mengacu pada tiga dimensi spasial, bahwa 3D menunjukkan suatu titik koordinat Cartesian X, Y dan Z. Penggunaan istilah 3D ini dapat digunakan di berbagai bidang dan sering dikaitkan dengan hal-hal lain seperti spesifikasi kualitatif tambahan (misalnya: grafis tiga dimensi, 3D video, film 3D, kacamata 3D, suara 3D). Istilah ini biasanya digunakan untuk menunjukkan relevansi jangka waktu tiga dimensi suatu objek, dengan gerakan perspektif untuk menjelaskan sebuah "kedalaman" dari gambar, suara, atau pengalaman taktil [1]

Virtual tour menggunakan konsep Virtual reality (VR) atau realitas maya. Secara sederhana, virtual reality menampilkan gambar 3D yang disimulasikan oleh komputer (computer-simulated environment) dan terlihat nyata dengan bantuan peralatan khusus [3]. Kelebihan utama dari virtual reality adalah pengalaman yang membuat pengguna merasakan sensasi dunia nyata dalam dunia maya [6]. Saat ini, teknologi virtual reality tidak hanya menggabungkan indra penglihatan dan pendengaran saja, namun indra lainnya juga merasakan sensasi nyata dari dunia maya. Penggabungan beberapa indra dalam mempresentasikan suatu konten dapat meningkatkan daya ingat dan ketertarikan orang terhadap konten tersebut [5].

Virtual reality sangat membantu dalam mensimulasikan sesuatu yang sulit untuk dihadirkan secara langsung dalam dunia nyata. Seperti halnya untuk bidang militer, virtual reality bisa menghadirkan simulasi perang secara virtual untuk latihan para tentara. Para tentara bisa merasakan sensasi berada di medan perang secara nyata dengan virtual reality. Tentunya ini bisa lebih praktis dan lebih ekonomis. Pemanfaatan virtual reality juga sangat membantu dalam bidang penerbangan. Dengan menggunakan virtual reality, para pilot bisa berlatih untuk menerbangkan pesawat secara virtual. Pilot bisa merasakan sensasi menerbangkan pesawat tanpa harus benar-benar menerbangkan pesawat sungguhan. Penggunaan virtual reality akan menghindari resiko terjadinya kecelakaan saat latihan [6].

Virtual tour guide ini merupakan aplikasi multimedia dengan material utamanya berupa gambar 3D dan audio sehingga metode yang tepat dalam penelitian ini adalah Multimedia Development Life Cycle (MDLC). MDLC menggunakan 5 tahapan yang tersusun secara sistematis. Adapun tahapan MDCL diilustrasikan pada Gambar 1.

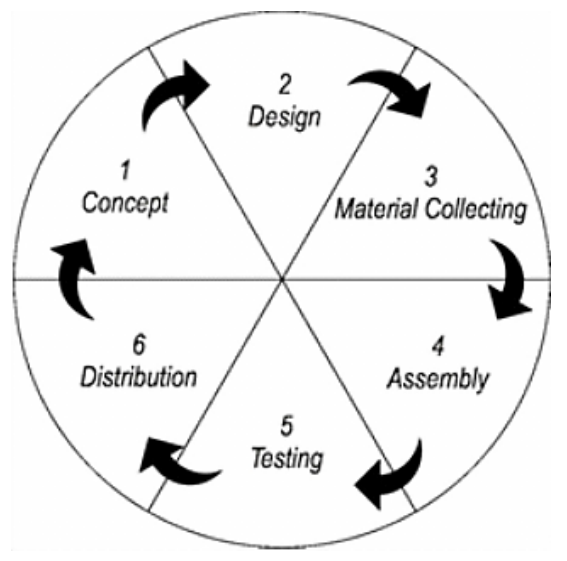

Gambar 1 Tahapan MDLC [2]

Tahap concept merupakan tahapan untuk menentukan tujuan pembuatan aplikasi serta menentukan pengguna aplikasi tersebut. Tahap design bertujuan untuk menggambarkan rangkaian cerita sehingga dapat 
dimengerti oleh pengguna. Material collecting adalah tahap pengumpulan bahan yang sesuai dengan kebutuhan berupa gambar dan audio. Tahap assembly adalah tahap pembuatan keseluruhan bahan multimedia. Tahap pengujian dilakukan untuk memastikan bahwa hasil pembuatan aplikasi multimedia sesuai dengan rencana. Tahap distribusi dilakukan setelah aplikasi dinyatakan layak pakai. Aplikasi akan disimpan dalam file apk dan dalam dijalankan pada smartphone android. Tahap evaluasi sistem termasuk ke dalam tahap ini [2].

Tujuan dari penelitian ini adalah membantu masyarakat mengenal keunggulan jurusan pada Fakultas MIPA menggunakan teknologi virtual reality. Masyarakat dapat mengenal lebih dalam tentang Fakultas MIPA tanpa terbatas pada waktu, tempat, dan biaya. Penerapan teknologi ini diharapkan dapat menyampaikan informasi tentang masing-masing jurusan di Fakultas MIPA kepada pengguna dengan lebih efektif. Penelitian ini membangun video tour guide Fakultas MIPA menggunakan teknologi virtual reality. Lingkungan Fakultas MIPA digambarkan dalam bentuk 3D, informasi tentang masing-masing jurusan di Fakultas MIPA disampaikan menggunakan voice. Video tour guide Fakultas MIPA selanjutnya disebut VirToMIPA Pengguna diberikan akses penuh untuk mengatur fasilitas/informasi apa saja yang ingin ditampilkan pada VirToMIPA.

\section{TEMUAN DAN DISKUSI}

Pengembangan VirToMIPA melalui 5 tahapan yaitu concept, design, material collecting, assembly, testing, dan distribution.

\subsection{Tahap Concept}

Tahapan ini merumuskan tujuan, pengguna, dan deskripsi dari aplikasi yang dibuat.

a. Tujuan pembuatan VirToMIPA yaitu sebagai media pengenalan Fakultas MIPA kepada calon mahasiswa pada khususnya dan masyarakat luas pada umumnya tentang keunggulan yang dimiliki oleh Fakultas MIPA.

b. Pengguna VirToMIPA adalah dosen, mahasiswa, calon mahasiswa, orang tua/wali mahasiswa, pihak yang berkepentingan dengan MIPA, dan masyarakat pada umumnya.

c. VirToMIPA dideskripsikan sebagai aplikasi multimedia berbasis teknologi virtual reality. VirToMIPA merupakan video tour guide yang menjelaskan tentang informasi-informasi penting dari setiap jurusan di Fakultas MIPA. Informasi berupa bentuk bangunan (3D), fasilitas yang berada pada setiap, bangunan, visi misi setiap jurusan, kegiatan kemahasiswaan, dan informasi-informasi penting lainnya. VirToMIPA dapat dioperasikan di smartphone android yang memiliki sensor gyroscope dan sensor magnetic field.

\subsection{Tahap Design}

Pembuatan VirToMIPA dilakukan dengan bantuan dua aplikasi utama. Aplikasi Sketch Up versi 19.0.685 yang digunakan untuk membuat bangunan 3D dan aplikasi Unity 3D untuk membuat virtual guide yang akan dijalankan pada sistem android. Aplikasi VirToMIPA membutuhkan perangkat tambahan untuk masuk ke lingkungan virtual dan berinteraksi langsung di lingkungan tersebut. Perangkat tambahan tersebut adalah kacamata VR Google CardBoard. Kebutuhan fungsional sistem digambarkan dalam bentuk use case diagram. Use case diagram yang dibangun terdiri dari satu actor sebagai pengguna aplikasi dan terdapat tiga use case yaitu menampilkan menu mulai tour, petunjuk penggunaan, tentang aplikasi. Use case diagram dapat dilihat pada Gambar 2. 


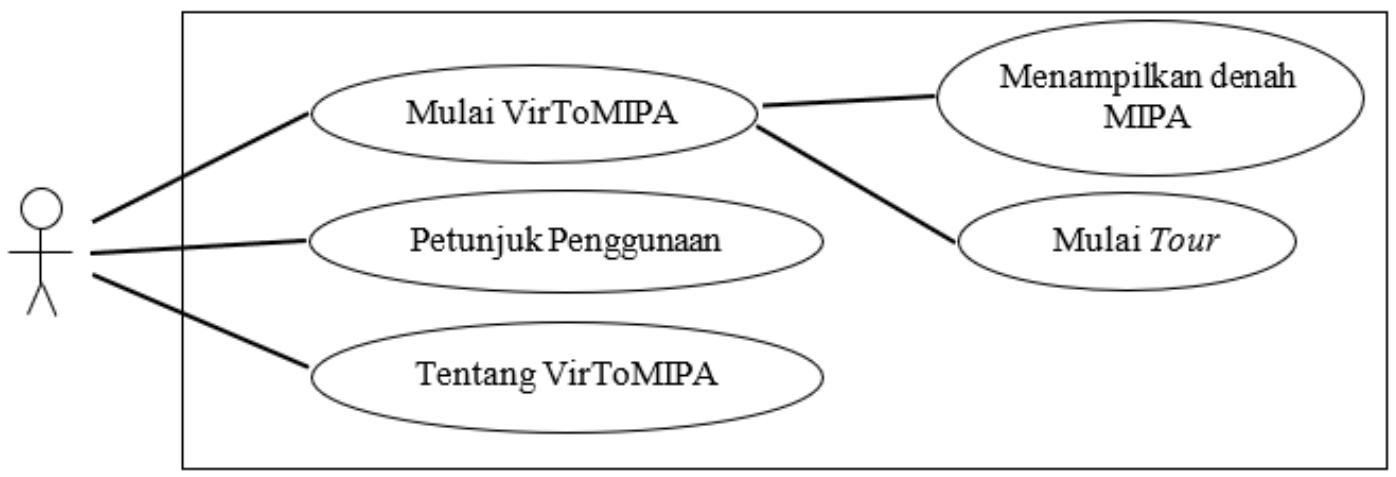

2 Use Case Diagram Aplikasi VirToMIPA

Gambar

Pada saat aplikasi dijalankan, aplikasi akan memunculkan menu utama. Pengguna dapat memilih menu Mulai VirToMIPA, Petunjuk Penggunaan, Tentang VirToMIPA, dan Keluar Aplikasi. Jika pengguna memilih menu Mulai VirToMIPA, maka pengguna dihadapkan dengan menu Menampilkan Denah MIPA dan Mulai Tour. Menu Menampilkan Denah MIPA menampilkan denah keseluruhan fakultas MIPA. Menu Mulai Tour akan membawa pengguna ke lingkungan virtual Fakultas MIPA. Pengguna dapat berkeliling ke semua jurusan di Fakultas MIPA. Jika pengguna memilih menu Petunjuk Penggunaan, maka pengguna akan mendapatkan penjelasan cara penggunaan aplikasi VirToMIPA. Jika pengguna memilih menu Tentang VirToMIPA, maka aplikasi akan menampilkan informasi tentang pembuat aplikasi VirToMIPA.

\subsection{Tahap Material Collecting}

Material untuk membangun virtual tour guide adalah

- Bangunan 3D gedung kuliah setiap jurusan, gedung praktikum, dan fasilitas lainnya pada Fakultas MIPA. Gedung 3D merupakan bentuk 3 dimensi dari gedung nyata yang ada di Fakultas MIPA. Gedung 3D dibangun menggunakan apliaksi skecth up. Hasil dari sketch up di konversi ke aplikasi unity.

- Audio dari guide diambil dengan bantuan software balabolka. Informasi tentang Fakultas MIPA diperoleh dari website Fakultas MIPA. Teks penjelasan tentang fakultas MIPA dibuat kemudian dimasukan ke software bolabolka. Teks tersebut akan berubah menjadi voice. Hasil dari software bolabolka ini berupa voice yang dapat disipan dalam file wav.

\subsection{Tahap Assembly}

Pada tahap ini, semua data-data yang diperlukan untuk membuat aplikasi VirToMIPA digabungkan menjadi satu untuk diterjemahkan dalam bentuk file apk. Data-data tersebut berupa gedung 3D dan semua informasi tentang Fakultas MIPA dalam bentuk audio. Output dalam bentuk file apk dapat dijalankan di smartphone android. Gambar 3 sampai Gambar 8 merupakan hasil pengembangan interface VirToMIPA. 
Vol 7 No. 2 , 2019

(C2019 Ilmu Komputer Unila Publishing Network all rights reserved

Jurnal Komputasi

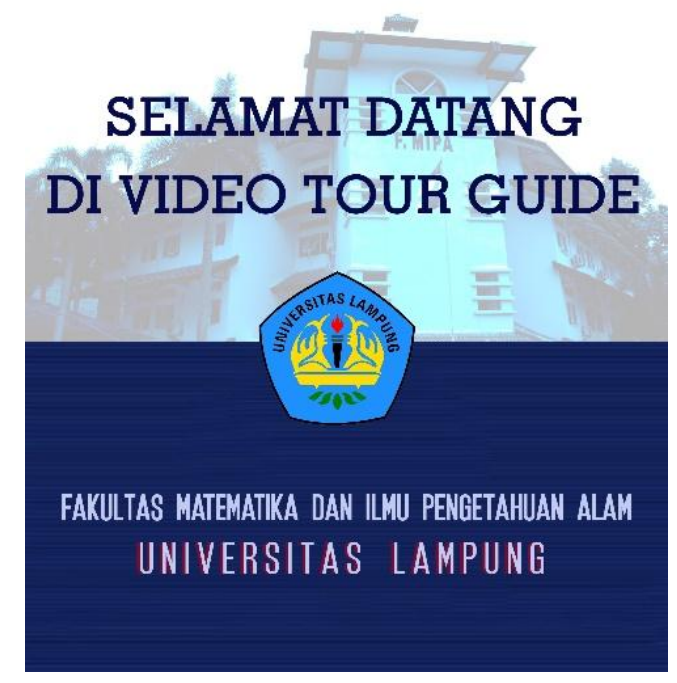

Gambar 3 Tampilan Awal Aplikasi VirToMIPA

Gambar 3 menampilkan gambar awal dari aplikasi VirToMIPA ini dijalankan. Tampilan awal muncul selama 5 detik.

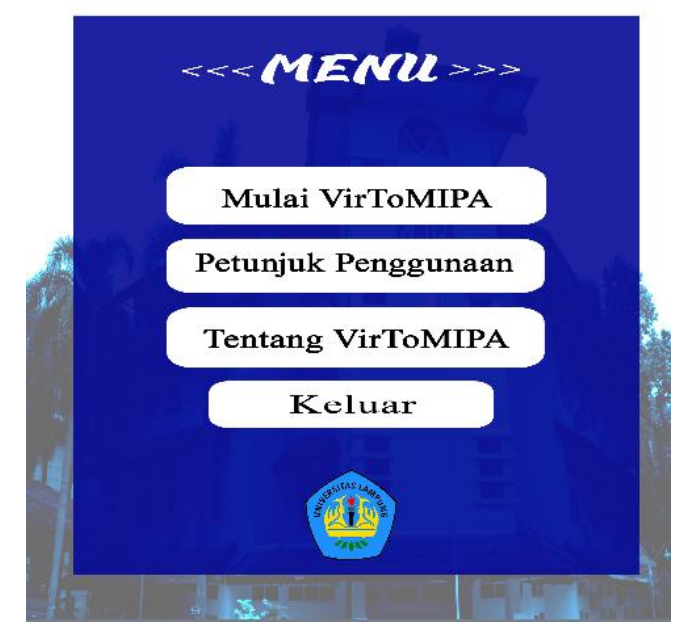

Gambar 4 Tampilan Menu Aplikasi VirToMIPA

Pada tampilan menu (Gambar 4), pengguna dapat memilih menu yang tersedia di aplikasi VirToMIPA. Apabila pengguna memilih menu Mulai VirToMIPA, pengguna akan diarahkan ke menu Menampilkan Denah MIPA (Gambar 5) dan menu Mulai Tour (Gambar 6). 
Vol 7 No. 2 , 2019

C2019 Ilmu Komputer Unila Publishing Network all rights reserved

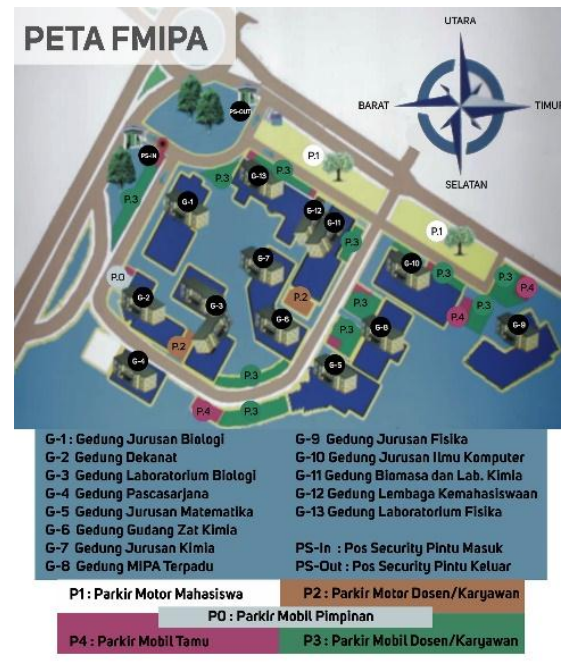

Gambar 5 Tampilan Denah 2D FMIPA

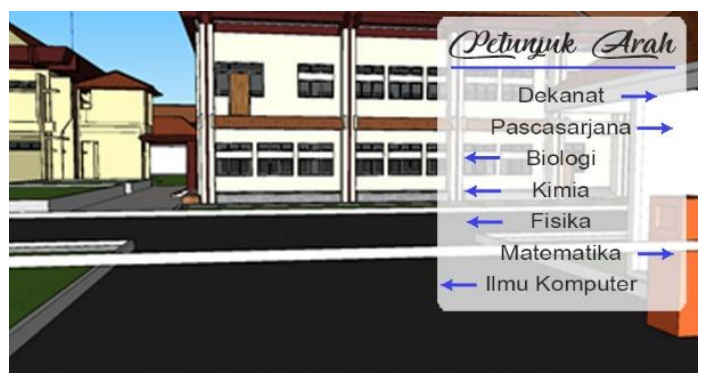

Gambar 6 Tampilan Menu Mulai Tour

Pada menu Mulai Tour, pengguna diberikan petunjuk arah secara langsung ke lokasi tertentu yang ingin dikunjungi di Fakultas MIPA (Gambar 6). Selanjutnya, pengguna harus fokus melihat ke arah yang ingin dituju dan aplikasi akan bergerak sesuai arah tersebut. Gambar 7 dan Gambar 8 merupakan tampilan eksterior dan interior gedung dekanat Fakultas MIPA.

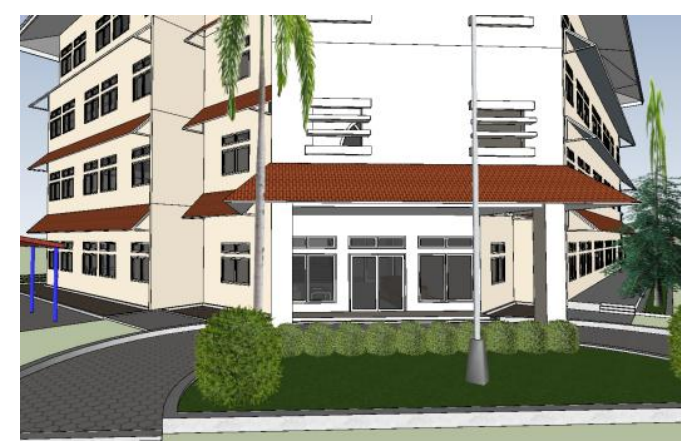

Gambar 7 Tampilan Luar Gedung Dekanat Fakultas MIPA 


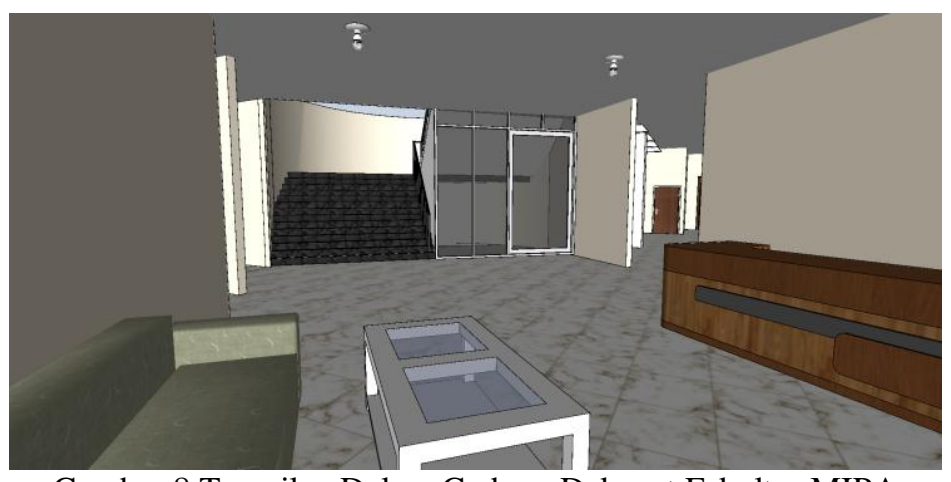

Gambar 8 Tampilan Dalam Gedung Dekanat Fakultas MIPA

Pengguna dapat langsung menjelajah gedung untuk mendapatkan gambaran dan informasi mengenai fasilitas yang dimiliki gedung tersebut.

\subsection{Tahap Testing}

Tahap testing merupakan tahap pengujian aplikasi VirToMIPA. Pengujian dilakukan menggunakan metode BlackBoard Testing. Hasil pengujian adalah aplikasi tidak dapat berjalan dengan baik pada smartphone dengan spesifikasi menengah ke bawah. Instalasi pada smartphone dengan prosesor OctaCore dengan kecepatan 1,6 GHz dan 2,0 GHz, RAM 2 GB dan 3 GB berjalan dengan lancar namun aplikasi yang telah diinstal di smartphone tersebut tidak dapat dijalankan. Analisis penyebab masalah yang ditemukan adalah versi software pendukung pembuatan file apk. Percobaan pembuatan file apk telah dilakukan menggunakan 3 versi unity 3D yaitu unity 3D versi 2018.2.12f1, versi 5.6.7f1, dan versi 5.6.4 p2. Namun, hasil pengujian menunjukkan kendala yang sama yaitu aplikasi hasil instalasi tidak dapat dijalankan dengan keterangan bahwa hardware smartphone tidak kompatibel dengan aplikasi VirToMIPA.

\section{SIMPULAN}

Berdasarkan pada pembahasan di atas, simpulan yang dicapai adalah virtual tour guide Fakultas MIPA berhasil dibuat dalam bentuk file android berekstensi apk. Kekurangan dalam aplikasi ini adalah aplikasi ini membutuhkan smartphone dengan spesifikasi khusus untuk dapat menjalankannya. Harapan untuk penelitian selanjutnya adalah kekurangan pada aplikasi VirToMIPA dapat diatasi menggunakan software pendukung dengan versi yang sesuai dan spesifikasi smartphone yang memadai.

\section{Ucapan Terima Kasih}

Terima kasih disampaikan kepada Universitas Lampung yang telah mendanai keberlangsungan penelitian dalam jurnal ini. Terima kasih juga disampaikan kepada Aristoteles, S.Si., M.Si., yang telah memberikan bantuan berupa data penelitian berupa objek 3D Fakultas MIPA Universitas Lampung. 
Vol 7 No. 2 , 2019

C2019 Ilmu Komputer Unila Publishing Network all rights reserved

Jurnal Komputasi

\section{DAFTAR PUSTAKA}

[1] Ardhianto, E., Hadikurniawati, W., \& Winarno, E. (2012, Juli). Augmented Reality Objek 3 Dimensi dengan Perangkat Artoolkit dan Blender. Jurnal Teknologi Informasi DINAMIK, 107-117.

[2] Binanto, I. (2010). Multimedia Dasar-Dasar Teori dan Pengembangannya. Yogyakarta: Andi.

[3] Fendra. (2012). Aplikasi Virtual Museum Berbasis 3D. Fakultas Ilmu Komputer Universitas Mercu Buana. Program Sarjana : Skripsi Diterbitkan.

[4] FMIPA. (2019). Sejarah - Faculty of mathematics and Natural Sciences University of Lampung. Retrieved Maret 9, 2019, from Fakultas Matematika dan Ilmu Pengetahuan Alam Universitas Unila: http://fmipa.unila.ac.id/profil/sejarah/

[5] Hooijdonk, C. v., Bosma, W., Krahmer, E., Maes, A., \& Theune, M. (2011). Retrieved Maret 9, 2019, from https://www.google.com/url?sa=t\&rct=j\&q=\&esrc=s\&source=web\&cd=1: Andi. \&ved=2ahUKEwiAnr3itPbgAhVUjuYKHVvDBy8QFjAAegQIBBAC\&ur $\mathrm{l}=\mathrm{https} \% 3 \mathrm{~A} \% 2 \mathrm{~F} \% 2 \mathrm{Fw} w$ whome.ewi.utwente.nl\%2F theune\%2FPUBS\%2 FIMIX-bookHooijdonk- etal.pdf\&usg=AOvVaw1yFiWgyWbo9CsDL6vapwkV

[6] Parindera, A. (2014). Mengenali Teknologi Virtual Reality Dan Perkembangannya. Retrieved from Ilmu Teknologi Informasi: http://ilmuti.org/wp- content/uploads/2017/02/AllanMengenali-Teknologi-Virtual-Reality- Dan-Perkembangannya.pdf.

[7] Wulansari, O. D., \& Heningtyas, Y. (2010). IMPLEMENTASI TEKNOLOGI AUGMENTED REALITY PADA GEDUNG-GEDUNG DI FAKULTAS MATEMATIKA DAN ILMU PENGETAHUAN ALAM UNIVERSITAS LAMPUNG, BANDAR LAMPUNG, INDONESIA. Jurnal Sains MIPA,16(3), 163-170.

[8] Wulur, H. W., Sentinuwo, S., \& Sugiarso, B. (2015). Aplikasi Virtual Tour Tempat Wisata Alam di Sulawesi Utara. Teknik Informatika,6. 